\title{
Effect of chronic endogenous hypergastrinaemia on pancreatic growth and carcinogenesis in the hamster
}

\author{
M Chu, E Kullman, J F Rehfeld, K Borch
}

\begin{abstract}
Background-To examine the effect of gastrin on spontaneous and induced pancreatic carcinogenesis in the hamster.

Methods and results-Two sets of experiments were carried out, one involving long term hypergastrinaemia and one involving cancer induction during hypergastrinaemia. The effect of hypergastrinaemia accomplished by gastric fundectomy was studied for eight months. Neither fundectomised hamsters nor sham operated controls developed premalignant or malignant pancreatic lesions. In the fundectomy group, the mean pancreatic weight, total protein content, and DNA content was increased by $28 \%, 25 \%$, and $25 \%$ respectively. No such increases were found in fundectomised animals receiving a cholecystokinin-B receptor antagonist during the last 24 days of the experiment. In the cancer induction study, the effect of fundectomy on $\mathrm{N}$-nitrosobis(2-oxopropyl)amine induced pancreatic carcinogenesis was studied for three months. There were no significant differences in the incidence or $\left[{ }^{3} \mathbf{H}\right]$-thymidine labelling index of focal pancreatic lesions between fundectomised and sham operated control animals.
\end{abstract}

Conclusions-Fundectomy with chronic hypergastrinaemia induces pancreatic hypertrophy, but does not enhance $\mathbf{N}$ nitrosobis(2-oxopropyl)amine induced pancreatic carcinogenesis in the hamster. The increases in growth were inhibited by a cholecystokinin-B receptor antagonist, indicating that the trophic effect of fundectomy is mediated by gastrin.

(Gut 1997; 40: 536-540)

Department of Surgery, University Hospital of Linköping, Linköping, Sweden M Chu

E Kullman

K Borch

Department of Clinical Chemistry,

Rigshospitalet,

University of

Copenhagen, Denmark

J F Rehfeld

Correspondence to:

Dr Kurt Borch

Department of Surgery,

University Hospital,

Sweden.

Accepted for publication 31 October 1996
Keywords: carcinogenesis, CCK-B receptor antagonist, gastric fundectomy, gastrin, hypertrophy, pancreas.

Gastrin, structurally related to cholecystokinin (CCK) and with an identical bioactive carboxyl terminal pentapeptide region, has been studied in the regulation of growth of the pancreas. Some studies reported that exogenously administered gastrin-17 and pentagastrin, as well as endogenous hypergastrinaemia accomplished by surgical procedures, stimulate growth of the exocrine pancreas in mice, rats, and hamsters. ${ }^{1-12}$ Gastrin (CCK-B) receptors have been found in guinea pig and dog pancreatic acini, ${ }^{13-15}$ calf pancreas, ${ }^{16}$ and normal human pancreas. ${ }^{17}{ }^{18} \mathrm{It}$ has also been shown in the human that gastrin17 augments pancreatic enzyme secretion at doses that are below the maximum for gastric acid secretion. ${ }^{19}$ These findings indicate that gastrin, at least under certain circumstances, may stimulate growth and function of the exocrine pancreas. However, studies in different rodents have shown that neither potent acid secretion inhibition leading to hypergastrinemia, ${ }^{20-23}$ nor gastrin-17 infusion in rats, ${ }^{24}$ causes pancreatic hypertrophy. Besides stimulating pancreatic growth, gastrin-17 and pentagastrin also stimulate growth of a rat pancreatic carcinoma cell line $\mathrm{e}^{25} 26$ and several human pancreatic cancer cell lines. ${ }^{27}$ In rats and hamsters, resection of the oxyntic gland area of the stomach (fundectomy) induces endogenous hypergastrinaemia. ${ }^{112328}$ As opposed to laborious and unphysiological exogenous gastrin administration or daily administration of drugs, fundectomy is useful for investigating long term effects of endogenous hypergastrinaemia. Recent studies with this model in the rat showed that long term fundectomy enhanced both spontaneous and induced carcinogenesis in acinar cells of the pancreas. ${ }^{12}{ }^{29}$ Pancreatic cancer induced with $\mathrm{N}$-nitrosobis(2-oxopropyl)amine (BOP) in the hamster is of ductal cell origin and thus resembles the most frequent type of pancreatic cancer in humans. ${ }^{30}$ The purpose of the present study was to investigate the effect of gastric fundectomy with chronic endogenous hypergastrinaemia on spontaneous and BOP induced pancreatic carcinogenesis in the hamster. No such study has been reported, although it is relevant, considering that epidemiological studies have shown that patients with pernicious anaemia, as well as patients who have undergone gastric resection, may run an increased risk of developing cancer in digestive organs other than the stomach, including the pancreas. ${ }^{31-34}$

\section{Methods}

ANIMALS

The study was approved by the local animal welfare committee. Eighty two 10 week old male Syrian golden hamsters (Bantin and Kingman, N Humberside, UK) with a mean body weight (SD) of $82(7) \mathrm{g}$ were used. The animals were kept at $20^{\circ} \mathrm{C}, 50 \%$ humidity, and a light/dark cycle of $12 / 12$ hours. They had 
free access to standard hamster food pellets (Lactamin, Vadstena, Sweden) and tap water.

LONG TERM HYPERGASTRINAEMIA STUDY

At 12 weeks of age, 34 hamsters were randomised to be operated on with resection of the oxyntic gland area of the stomach (fundectomy). The vagal trunks were preserved, and gastric continuity restored by anastomosis between the antrum and the non-oxyntic rumen of the proximal stomach. ${ }^{23}$ Ten animals were sham operated with gastrotomy in the oxyntic gland area (controls). Ketamine hydrochloride (Ketalar, Parke-Davis, Barcelona, Spain) and xylazin chloride (Rompun, Bayer, Malmö, Sweden) given intraperitoneally were used for general anaesthesia. The animals were fasted for 15 hours before the operation. Postoperative fasting lasted 24 hours during which the animals received two subcutaneous injections of $6 \mathrm{ml} 0.9 \%$ saline. Long term postoperative mortality was $21 \%$ after fundectomy and $0 \%$ after sham operation. Eight months after the operation, all animals were killed by exsanguination under general anaesthesia and after fasting for 15 hours. During 24 days before being killed, 10 of the 27 fundectomised animals were randomised to receive the CCK-B receptor antagonist L365,260 (kindly supplied by MSD, West Point, PA, USA) in a dose of $50 \mu \mathrm{g} / \mathrm{kg} /$ hour in $70 \%$ dimethyl sulphoxide by osmotic minipump (Alzet 2002, ALZA, Palo Alto, CA, USA) deposited intraperitoneally. The remaining 17 fundectomised and 10 sham operated animals received vehicle by osmotic minipump. The pumps were changed under general anaesthesia after 12 days. This resulted in 10 fundectomised and L365,260 treated, 17 fundectomised, and 10 sham operated hamsters for further studies. When the animals were killed, fasting blood samples were collected in EDTA tubes from the inferior vena cava, centrifuged, and stored at $-70^{\circ} \mathrm{C}$ until analysed.

HYPERGASTRINAEMIA-NITROSAMINE STUDY At 10 weeks of age, 38 hamsters received a single injection of $\mathrm{N}$-nitrosobis(2-oxopropyl) amine (BOP; Ash Stevens, Detroit, MI, USA) subcutaneously at a dose of $20 \mathrm{mg} / \mathrm{kg}$ body weight. Two weeks after BOP treatment, these animals were randomised to undergo either fundectomy $(n=23)$ or sham operation $(n=15)$. Long term postoperative mortality was $17 \%$ after fundectomy and $0 \%$ after sham operation. Three months (12 weeks) after BOP treatment (10 weeks after the operation), all animals were killed by exsanguination under general anaesthesia. During five days before being killed, eight of the 19 fundectomised animals were randomised to receive $\mathrm{L} 365,260$ as described above. The remaining 11 fundectomised and 15 sham operated animals received vehicle. This resulted in eight fundectomised and L365,260 treated, 11 fundectomised, and 15 sham operated hamsters for further studies. One hour before being killed, each hamster received $\left[{ }^{3} \mathrm{H}\right]$-thymidine through the internal jugular vein (specific activity $20 \cdot 0 \mathrm{Ci} / \mathrm{mmol}, \mathrm{Du}$ Pont Scandinavia AB, Stockholm, Sweden) at a dose of $1 \mu \mathrm{Ci} / \mathrm{g}$ body weight.

HISTOLOGICAL ANALYSIS AND AUTORADIOGRAPHY

The pancreas and all other organs were removed and examined macroscopically. The pancreas was trimmed of adherent fat and weighed and the splenic lobe was fixed in $4 \%$ buffered formalin for histological studies. Tissue specimens were embedded in Technovit 7100 plastic (Heraeus Kulzer $\mathrm{GmbH}$, Wehrheim, Germany), cut in $2 \mu \mathrm{m}$ thick sections and stained with haematoxylin and eosin. Pancreatic lesions, including carcinoma and early putative preneoplastic lesions (tubular ductal complex, cystic ductal complex and intermediate ductal complex), were searched for and classified according to previously described criteria. ${ }^{35-37}$ The splenic lobe was blindly screened for such lesions with a point counting method, using a magnification of $\times 100$ and $100 \mu \mathrm{m}$ between the points. In each animal, a total of 40000 points were counted over consecutive visual fields across the tissue sections. For autoradiographical studies in BOP treated animals, $2 \mu \mathrm{m}$ thick plastic embedded tissue sections from the splenic lobe were coated with Kodak $\mathrm{NTB}_{2}$ emulsion (Eastman Kodak, Rochester, NY, USA), developed after four weeks of incubation in darkness at $4^{\circ} \mathrm{C}$, and counterstained with haematoxylin and eosin. The $\left[{ }^{3} \mathrm{H}\right]$-thymidine labelling index of pancreatic lesions was determined blindly with a magnification of $\times 1000$. Five or more grains overlying a nucleus were regarded as significant labelling. In each animal, a total of 3500 labelled and nonlabelled nuclei were counted in consecutive areas of the lesions. Labelling index was expressed as percentage of labelled nuclei.

DNA AND PROTEIN ANALYSIS

After removing the splenic lobe for histological examination, the rest of the pancreas (gastric and duodenal lobe and head) was weighed, quick frozen, and stored at $-70^{\circ} \mathrm{C}$ for DNA and protein analysis. These were analysed according to the methods described by Labarca and Paigen ${ }^{38}$ and Lowry et $a^{39}$ respectively.

\section{PLASMA GASTRIN AND CHOLECYSTOKININ} ASSAY

The concentrations of gastrin in plasma were measured by a specific radioimmunoassay, as previously described. ${ }^{40}{ }^{41}$ The concentrations of CCK in plasma were measured by radioimmunoassay using C-terminal directed antiserum without cross reactivity towards gastrin. ${ }^{42}$ The assays have been described in detail elsewhere. ${ }^{434}$

\section{STATISTICAL ANALYSIS}

Results are expressed as mean (SEM). Two tailed Student's $t$ test and the Mann-Whitney 

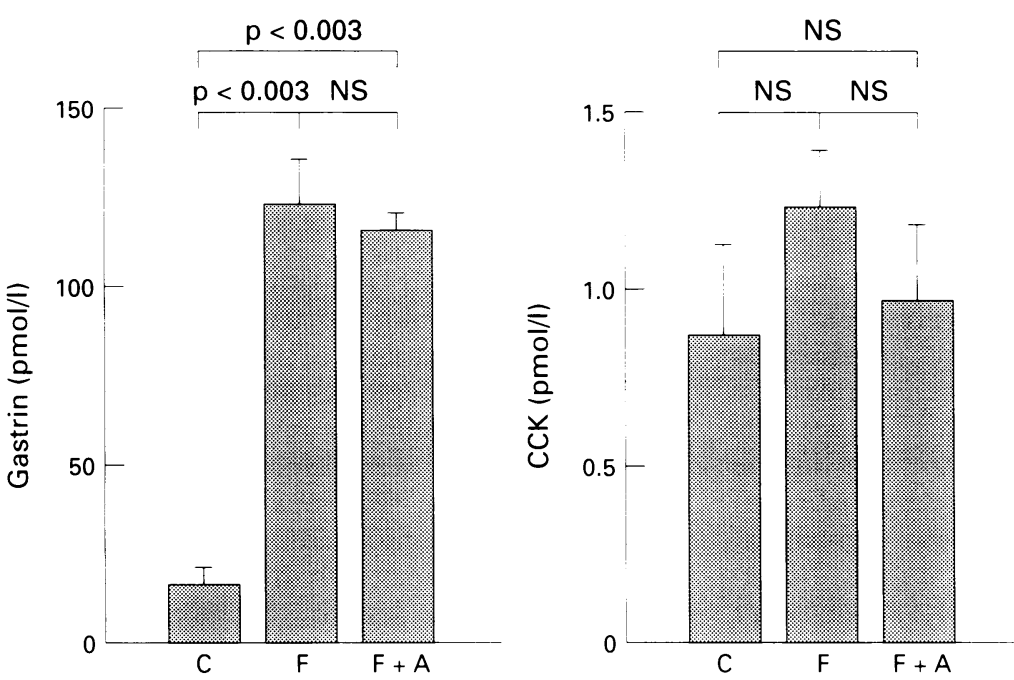

Figure 1: Mean (SEM) of the fasting plasma gastrin and cholecystokinin (CCK) concentrations in groups of sham operated $(C)(n=6)$, fundectomised $(F)(n=6)$, or fundectomised and $L 365,260$ treated $(F+A)(n=6)$ hamsters eight months after the operation.

\section{Results}

LONG TERM HYPERGASTRINAEMIA STLDY

Figure 1 shows the fasting plasma concentrations of gastrin and CCK at the time of death. Fundectomised animals had hypergastrinaemia, whereas basal plasma CCK concentrations did not differ significantly between the groups. There were no significant differences in body weight between the groups at the time of death (Table I). The mean pancreatic weight was $28 \%$ higher in the fundectomy group than in the sham operated group (Table I). The mean total pancreatic content of protein and DNA was increased by $25 \%$ and $25 \%$ respectively in the fundectomy group (Table I). No such increases were found in fundectomised animals receiving L365,260 over a 24 day period. No focal pancreatic lesions were found on microscopical examination in fundectomised and sham operated hamsters, and no macroscopical changes were found in the liver or other organs.

$\mathrm{U}$ test were used. Differences were considered significant when $\mathrm{p}<0.05$ in both tests. Unless otherwise mentioned, given values of $p$ are those derived from the Mann-Whitney $\mathrm{U}$ test. Fisher's exact test was used to evaluate differences in proportions.

TABLE I Mean (SEM) of the body weight (BW), pancreatic weight (PW), total pancreatic protein, and total pancreatic DNA in groups of sham operated (control), fundectomised, and fundectomised plus L365,260 treated (fundectomy L365,260) hamsters eight months after the operation

\begin{tabular}{llllll}
\hline Group & $\begin{array}{l}\text { No of } \\
\text { animals }\end{array}$ & $B W(g)$ & $P W(m g)$ & Protein $(m g)$ & DNA (mg) \\
\hline Control & 10 & $113(3)$ & $335(8)$ & $37 \cdot 5(1 \cdot 2)$ & $2 \cdot 4(0 \cdot 1)$ \\
Fundectomy & 17 & $110(3)^{\mathrm{b}}$ & $428(9)^{\mathrm{a}}$ & $46 \cdot 8(1 \cdot 6)^{\mathrm{a}}$ & $3 \cdot 0(0 \cdot 1)^{\mathrm{a}}$ \\
Fundectomy L365,260 & 10 & $112(3)^{\mathrm{b}}$ & $356(14)^{\mathrm{b}}$ & $39 \cdot 7(1 \cdot 9)^{\mathrm{b}, \mathrm{c}}$ & $2 \cdot 5(0 \cdot 1)^{\mathrm{b}}$ \\
\hline
\end{tabular}

a: $\mathrm{p}<0.001$; b: non-significant $v$ control group (Mann-Whitney $U$ test)

c: $\mathrm{p}<0.001$; $\mathrm{d}$ p $<0.01 ; \mathrm{e}: \mathrm{p}<0.05 v$ fundectomy group (Mann-Whitney U test).

TABLE II Mean (SEM) of the body weight (BW), pancreatic weight (PW), total pancreatic protein, and total pancreatic DNA in groups of sham operated (control), fundectomised, and fundectomised plus L365,260 treated (fundectomy L365,260) hamsters 12 weeks after a single injection of N-nitrosobis(2-oxopropyl) amine

\begin{tabular}{llllll}
\hline Group & $\begin{array}{l}\text { No of } \\
\text { animals }\end{array}$ & $B W(g)$ & $P W(m g)$ & Protein $(m g)$ & DNA (mg) \\
\hline Control & 15 & $101(3)$ & $327(6)$ & $36 \cdot 6(1 \cdot 4)$ & $2 \cdot 3(0 \cdot 1)$ \\
Fundectomy & 11 & $98(3)^{\mathrm{d}}$ & $435(11)^{\mathrm{a}}$ & $48 \cdot 4(2 \cdot 2)^{\mathrm{a}}$ & $3 \cdot 0(0 \cdot 1)^{\mathrm{a}}$ \\
Fundectomy L365,260 & 8 & $99(3)^{\mathrm{d}}$ & $419(11)^{\mathrm{a} \cdot \mathrm{c}}$ & $46 \cdot 6(2 \cdot 4)^{\mathrm{b}, \mathrm{c}}$ & $2 \cdot 7(0 \cdot 1)^{\mathrm{c}, \mathrm{e}}$ \\
\hline
\end{tabular}

a: $\mathrm{p}<0.001$; b: $\mathrm{p}<0.01$; $\mathrm{c}: \mathrm{p}<0.05$; : non-significant $v$ contol group (Mann-Whitney $\mathrm{U}$ test). e: non-significant $v$ fundectomy group (Mann-Whitney $\mathrm{U}$ test).

TABLE III Incidence and $\left[{ }^{3} \mathrm{H}\right]$-thymidine labelling index (LI) of pancreatic lesions in groups of sham operated (control), fundectomised, and fundectomised plus L365,260 treated (fundectomy L365,260) hamsters 12 weeks after a single injection of N-nitrosobis (2-oxopropyl) amine

\begin{tabular}{llllll}
\hline & \multicolumn{4}{l}{ No of animals with } \\
\cline { 3 - 5 } Group & $\begin{array}{l}\text { No of } \\
\text { animals }\end{array}$ & $\begin{array}{l}\text { Tubular } \\
\text { ductal } \\
\text { complex }\end{array}$ & $\begin{array}{l}\text { Cystic } \\
\text { ductal } \\
\text { complex }\end{array}$ & $\begin{array}{l}\text { Intermediate } \\
\text { ductal } \\
\text { complex }\end{array}$ & LI (\%) \\
\hline Control & 15 & 5 & 5 & 5 & $0 \cdot 9(0 \cdot 2)$ \\
Fundectomy & 11 & $5^{\mathrm{a}}$ & $5^{\mathrm{a}}$ & $5^{\mathrm{a}}$ & $1 \cdot 4\left(0 \cdot 2^{\mathrm{b}}\right.$ \\
Fundectomy L 365,260 & 8 & $4^{\mathrm{a}}$ & $4^{\mathrm{a}}$ & $4^{\mathrm{a}}$ & $1 \cdot 1(0 \cdot 3)^{\mathrm{b}, \mathrm{c}}$ \\
\hline
\end{tabular}

a: non-significant $v$ control group (Fisher exact test)

b: non-significant $v$ control group (Mann-Whitney $\mathrm{U}$ test)

c: non-significant $v$ fundectomy group (Mann-Whitnev $\mathrm{U}$ test).
HYPERGASTRINAEMIA-NITROSAMINE STUDY

No significant differences in body weight were seen between the groups at the time of death (Table II). The mean pancreatic weight was increased by $33 \%$ in the fundectomy group compared with the sham operated group. The mean total pancreatic content of protein and DNA was increased by $32 \%$ and $30 \%$ respectively in the fundectomy group. Fundectomised animals receiving L365,260 over a five day period showed similar increases (Table II). Putative preneoplastic pancreatic lesions, such as tubular ductal complex, cystic ductal complex, and intermediate ductal complex, were diagnosed on microscopical examination in nine $(47 \%)$ of the 19 fundectomised animals, including those treated with L 365,260, and in five $(33 \%)$ of the 15 sham operated animals (Table III). Pancreatic carcinoma was not found in any animal. There were no significant differences in the $\left[{ }^{3} \mathrm{H}\right]$-thymidine labelling index of pancreatic lesions between the groups (Table III, Fig 2). No macroscopical changes were found in the liver or other organs.

\section{Discussion}

Fundectomy did not cause any significant change in the basal plasma CCK concentrations, which could have been a source of error. In agreement with previous studies in hamsters ${ }^{11}$ and rats, ${ }^{12}$ the present study showed that fundectomy induces endogenous hypergastrinaemia with exocrine pancreatic hyperplasia and hypertrophy which obviously persists after eight months. The hypertrophy was reversed by infusion of a CCK-B receptor antagonist during 24 days, indicating that the trophic effect of fundectomy on the pancreas is mediated by gastrin. In the study involving BOP, pancreatic growth was not significantly reduced by infusion of the CCK-B receptor antagonist over five days, indicating that more than five days are needed to reverse gastrin 


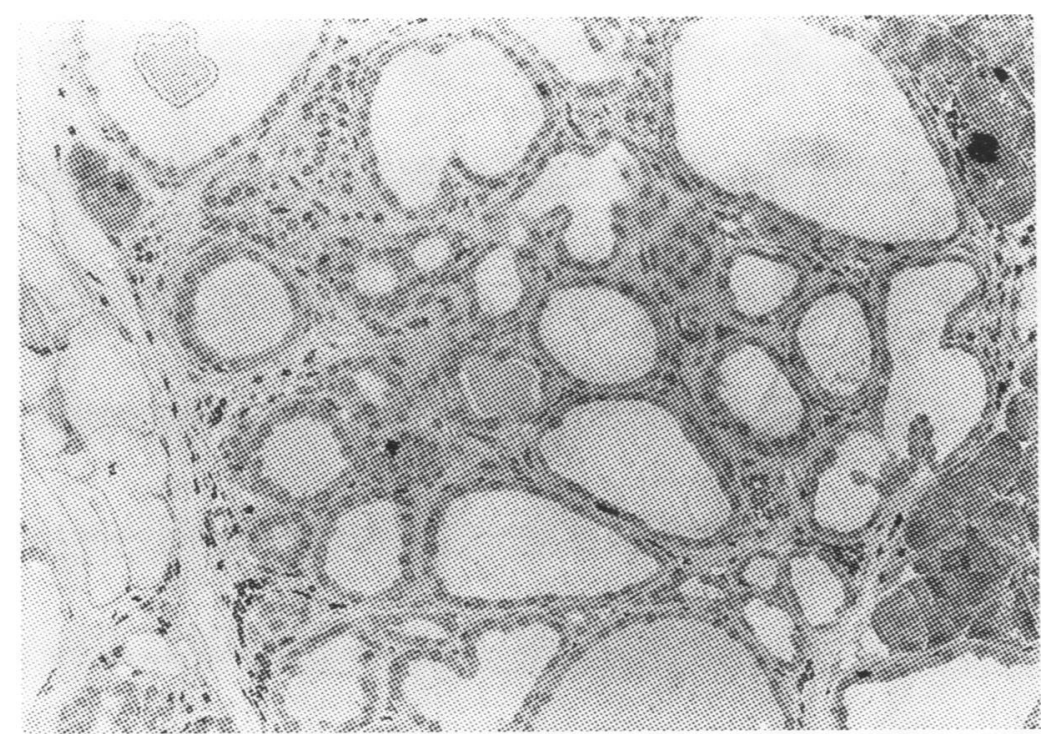

Figure 2: Autoradiographed pancreatic section from a fundectomised hamster three months after a single dose of $\mathrm{N}$-nitrosobis (2-oxopropyl) amine. Epithelial cells with nuclear labelling are present in the ductal complexes (originally $\times 200$ ).

induced hypertrophy. Whether gastrin has a trophic effect on the exocrine pancreas is a matter of controversy. Among the studies showing no pancreaticotrophic effect of gastrin, ${ }^{20-24}$ one used fundectomy or antrum exclusion to accomplish hypergastrinaemia. ${ }^{23}$ In that study, fundectomy over a 10 week period in rats did not cause pancreatic hypertrophy, whereas antrum exclusion did. Studies on the long term effect of fundectomy on the pancreas in hamsters have not previously been reported. In rats, long term fundectomy over 14 months caused an increase in the mean pancreatic weight by $31 \%,{ }^{12}$ which should be compared with $28 \%$ in the hamster after eight months in the present study. Furthermore, long term fundectomy in the rat caused development of potentially premalignant exocrine pancreatic lesions, ${ }^{12}$ which were not seen eight months after fundectomy in the present study. Accordingly, it seems that, unlike the rat, the hamster does not develop premalignant pancreatic lesions on the basis of endogenous hypergastrinaemia itself. With regard to the effects of gastrin on experimental pancreatic carcinogenesis, data are very limited. ${ }^{29}{ }^{45}$ Previous studies showed that gastric fundectomy or split gastrojejunostomy with hypergastrinaemia enhanced azaserine induced pancreatic carcinogenesis in the rat. ${ }^{29}{ }^{45}$ In the present study, however, fundectomy did not significantly influence the incidence or labelling index of pancreatic lesions, indicating that early preneoplastic pancreatic lesions in the hamster are not sensitive to endogenous gastrin. Considering pancreatic cancer, gastrin-17 and pentagastrin have been shown to stimulate the growth of a rat carcinoma cell line ${ }^{25} 26$ and several human cancer cell lines. ${ }^{27}$ Specific gastrin binding and CCK-B receptors have also been found in a rat pancreatic carcinoma, ${ }^{46} 47$ and human pancreatic cancer or cancer cell lines. ${ }^{1848} 49$ The effect of gastrin on in vivo established pancreatic cancer in the hamster, however, is still unknown and needs to be further investigated.
We conclude that fundectomy with chronic endogenous hypergastrinaemia induces persistent pancreatic hypertrophy, but does not enhance BOP induced early pancreatic carcinogenesis in hamsters. The increases in growth were significantly reduced by administering a CCK-B receptor antagonist, indicating that the trophic effect of fundectomy is mediated by gastrin acting through the CCK-B receptor.

The kind advice of Professor Dr Parviz M Pour, Department of Pathology, University of Nebraska Medical Center, Omaha, NE, USA, on the histological diagnosis is greatly appreciated. The study was supported by grants from the Swedish National Cancer Association and Cancer Funds of Östergötland County, Sweden.

1 Mayston PD, Barrowman JA. Influence of chronic administration of pentagastrin on the rat pancreas. auministration of pentagal of Experimental Physiology 1971; 56: Quarterly

2 Reber HA, Johnson F, Deveney K, Montgomery C, Way LW. Trophic effects of gastrin on the exocrine pancreas in rats. I Surg Res 1977; 22: 554-60.

3 Petersen H, Solomon T, Grossman M. Effect of chronic pentagastrin, cholecystokinin, and secretin on pancreas of rats. Am $\mathcal{F}$ Physiol 1978; 234: E286-93.

4 Majumdar APN, Goltermann N. Chronic administration of pentagastrin. Digestion 1979; 19: 144-7.

5 Dembinski AB, Johnson LR. Growth of pancreas and gastrointestinal mucosa in antrectomized and gastrintreated rats. Endocrinology 1979; 105: 769-73.

6 Dembinski AB, Johnson LR. Stimulation of pancreatic growth by secretin, caerulein, and pentagastrin. Endogrowth by secretin, caerul

7 Johnson LR. Effects of gastrointestinal hormones on pancreatic growth. Cancer 1981; 47: 1640-5.

8 Balas D, Senegas-Balas F, Pradayrol L, Vayssette J, Bertrand C, Ribet A. Long-term comparative effect of cholecystokinin and gastrin on mouse stomach, antrum, intestine, and exocrine pancreas. American fournal of Anatomy 1985; 174: 27-43.

9 Solomon TE, Morisset J, Wood JG, Bussjaeger LJ. Additive interaction of pentagastrin and secretin on pancreatic growth in rats. Gastroenterology 1987; 92: 429-35.

10 Konturek SJ, Dembinski A, Warzecha Z, Jaworek J. Konturek PK, Cai R-Z, Schally AV. Antagonism of receptors for bombesin, gastrin and cholecystokinin in pancreatic secretion and growth. Digestion 1991; 48: pancrea

11 Chu M, Rehfeld JF, Borch K. Effects of gastric fundectomy and antrectomy on the exocrine pancreas in the hamster. Int $\mathcal{F}$ Pancreatol 1992; 12: 139-44.

12 Chu M, Franzen L, Sullivan S, Wingren S, Rehfeld JF, Borch K. Pancreatic hypertrophy with acinar cell nodules after longterm fundectomy in the rat. Gut 1993; 34: 988-93.

13 Yu DH, Noguchi M, Zhou ZC, Villanueva ML, Gardner JD, Jensen RT. Characterization of gastrin receptors on guinea pig pancreatic acini. Am 7 Physiol 1987; 253: G793-801.

14 Fourmy D, Zahidi A, Fabre R, Pradayrol L, Ribet A. Receptors for cholecystokinin and gastrin peptides display
specific binding properties and are structurally different specific binding properties and are structurally different
in guinea-pig and dog pancreas. Eur $\mathcal{F}$ Biochem 1987; 165: in guinea-pig

15 Yu DH, Huang SC, Wank SA, Mantey S, Gardner JD, Jensen RT. Pancreatic receptors for cholecystokinin: evidence for three receptor classes. Am $\mathcal{F}$ Physiol 1990, 258: G86-95.

16 Lemeuth V, Philouzerome V, Lehuerouluron I, Formal M Vaysse N, Gespach C, et al. Differential expression of A-subtype and B-subtype of cholecystokinin gastrin receptors in the developing calf pancreas. Endocrinology 1993; 133: 1182-91.

17 de Weerth A, Pisegna JR, Huppi K, Wank SA. Molecular cloning, functional expression and chromosomal localization of the human cholecystokinin A receptor. localization of the human cholecystokinin A

18 Zhou WG, Povoski SP, Tsuei BJ, Bell RH. Gene expression of the cholecystokinin-A receptor and the cholecytokinin$B$ (gastrin) receptor in human pancreatic carcinomas. Gastroenterology 1994; 106: A331.

19 Valenzuela JE, Walsh JH, Isenberg JI. Effect of gastrin on pancreatic enzyme secretion and gallbladder emptying in man. Gastroenterology 1976; 71: 409-11.

20 Håkanson R, Blom H, Carlsson E, Larsson H, Ryberg B, Sundler $F$. Hypergastrinaemia produces trophic effects in stomach but not in pancreas and intestines. Regul Pept 1986; 13: 225-33.

21 Håkanson $\mathrm{R}$, Axelson $\mathrm{J}$, Ekman R, Sundler F. Hypergastrinemia evoked by omeprazole stimulates growth of gastric mucosa but not of pancreas or intestines in hamster, guinea pig and chicken. Regul Pept 1988; 23: $105-15$. 
22 Niederau $C$, Niederau $M$, Klonowski $H$, Lüthen $R$, Ferrell LD. Effect of hypergastrinemia and blockade of gastrin-receptors on pancreatic growth in the mouse. Hepatogastroenterology 1995; 42: 423-31.

23 Oscarson J, Håkanson $R$, Liedberg G, Lundquist $G$ Sundler F, Thorell J. Variated serum gastrin concentration: trophic effects on the gastrointestinal tract of the rat. Acta Physiol Scand 1979; (suppl 475): 3-27.

24 Ryberg B, Axelson R, Håkanson R, Sundler F, Mattsson $H$ Trophic effects of continuous infusion of [ $\left.\mathrm{Leu}^{15}\right]$-gastrin17 in the rat. Gastroenterology 1990; 98: 33-8.

25 Seva C, DeVries L, Scemama JL, Sarfati P, Nicolet TG, Pradayrol L, Vaysse N. Gastrin modulates growth of a rat acinar pancreatic cell line: receptor analysis and signal transduction. Digestion 1990; 46 (suppl 2): 166-9.

26 Seva C, Scemama JL, Bastié MJ, Pradayrol L, Vaysse N. Lorglumide and loxiglumide inhibit gastrin-stimulated DNA synthesis in a rat tumoral acinar pancreatic cell line (AR42J) Cancer Res 1990; 50: 5829-33.

27 Smith JP, Fantaskey AP, Liu GZ, Zagon IS. Identification of gastrin as a growth peptide in human pancreatic cancer. of gastrin as a growth peptide in hu

28 Tatsuta $M$, Itoh T, Okuda S, Tamura $H$, Yamamura $H$ Effect of fundusectomy on serum and antral gastrin level in rats. Gastroenterology 1977; 72: 78-81.

29 Chu M, Franzen L, Sullivan S, Rehfeld JF, Ihse Borch K. Effects of pancreaticobiliary diversion and gastric fundectomy on azaserine-induced pancreatic carcinogenesis in the rat. Pancreas 1993; 8: 330-7.

30 Pour PM, Runge RG, Birt D, Gingell R, Lawson L, Nagel D, Wallcave L, Salmasi SZ. Current knowledge of pancreatic carcinogenesis in the hamster and its relevance to the human disease. Cancer $1981 ; 47: 1573-87$.

31 Caygill C, Hill M, Craven J, Hall R, Miller C. Relevance of gastric achlorhydria to human carcinogenesis. In: $\mathrm{H}$, eds. N-nitroso compounds: occurrence, biological effects $\mathrm{H}$, eds. N-nitroso compounds: occurrence, biological effects and relevance to human cancer. No 57. Lyon: Intern

32 Borch K, Kullman E, Ledin T, Ihse I. Increased incidence of pancreatic neoplasia in pernicious anemia. World $\mathcal{F}$ Sur 1988; 12: 866-70

33 Talley NJ, Chute CG, Larson DE, Epstein R, Lydick EG Melton LJ. Risk of colorectal adenocarcinoma in pernicious anemia. Ann Intern Med 1989; 111: 738-42.

34 Caygill CPJ, Hill MJ, Hall CN, Kirkham JS, Northfield TC. Increased risk of cancer at multiple sites after gastric surgery for peptic ulcer. Gut 1987; 28: 924-8.

35 Pour PM, Althoff J, Takahashi M. Early lesions of pancreatic ductal carcinoma in the hamster model. $A m \mathcal{F}$ Pathol 1977; 88: 291-308.
36 Moore MA, Takahashi M, Ito N, Bannasch P. Early lesions during pancreatic carcinogenesis induced in Syrian hamster by DHPN or DOPN. I. Histologic, histochemical and radioautographic findings. Carcinogenesis

37 Woutersen RA, van Garderen-Hoetmer A, Longnecker DS Characterization of a 4-month protocol for the quantitation of BOP-induced lesions in hamster pancreas and its application in studying the effect of dietary fat. Carcinogenesis 1987; 8: 833-7.

38 Labarca C, Paigen K. A simple, rapid and sensitive DNA assay procedure. Anal Biochem 1980; 102: 344-52.

39 Lowry OH, Rosebrough NJ, Farr AL, Randall RJ. Protein measurement with the folin phenol reagent. $\mathcal{F}$ Biol Chem 1951; 193: 265-75.

40 Rehfeld JF, Stadil F, Rubin F. Production and evaluation of antibobies for the radioimmunoassay of gastrin. Scand of antin Lab Invest 1972; 32: 221-32.

41 Rehfeld JF. Gastrins in serum. Scand $\mathcal{f}$ Gastroenterol 1973 8: 577-83.

42 Rehfeld JF. Immunochemical studies on cholecystokinin. I. Development of sequence-specific radioimmunoassays for porcine triacontatriapeptide cholecystokinin. $\mathcal{f}$ Biol Chem 1978; 253: 4016-21.

43 Byrnes DJ, Henderson L, Borody T, Rehfeld JF. Radioimmunoassay of cholecystokinin in human plasma. Clin Chim Acta 1981; 111: 81-9.

44 Cantor P. Evaluation of a radioimmunoassay for cholecystokinin in human plasma. Scand $\mathcal{F}$ Clin Lab Invest 1986; 46: 213-21.

45 Watanapa , Flaks B, Oztas H, Deprez PH, Calam J Williamson RCN. Duodenogastric reflux enan J, growth and carcinogenesis in the rat pancreas. $\mathrm{Br} \mathcal{F}$ Surg growth and carcin.

46 Povoski SP, Zhou WG, Longnecker DS, Bell RH. Temporal expression of the gastrin (CCK-B) receptor during azaserine-induced pancreatic carcinogenesis. Pancreas 1993; 8: 615-21.

47 Zhou WG, Povoski SP, Bell RH. Overexpression of messenger RNA for cholecystokinin-A receptor and novel expression of messenger RNA for gastrin (cholecystokinin-B) receptor in azaserine-induced rat pancreatic carcinoma. Carcinogenesis 1993; 14: 2189-92.

48 de Weerth A, von Schrenck T, Mirau S, Readler A Greten $H, K a l t h o f f H$. Human pancreatic cancer cell lines express the CCK-B/gastrin receptor. Gastroenterology 1994; 106: A289.

49 Povoski SP, Zhou WG, Longnecker DS, Bell RH. Novel expression of gastrin (CCK-B) receptors in pancreatic carcinomas and dysplastic pancreas from transgenic mice. Am ₹ Surg 1994; 167: 120-7. 